\title{
FENG SHUI DALAM MENDESAIN LOGO
}

\author{
Monica \\ Jurusan Desain Komunikasi Visual, Fakultas Komunikasi dan Multimedia, Bina Nusantara University \\ Jln. K.H. Syahdan No. 9, Palmerah, Jakarta Barat 11480 \\ monica@binus.edu
}

\begin{abstract}
A good logo is a reflection of a corporate identity, vision and mission, as well as a summary of the company's character. Feng shui is the ancient Chinese science of topography is believed to affect the success of making a good logo. According to Feng shui, every color, shape, letters, and numbers can affect the energy contained in the company logo. And these factors also have a grouping of the elements of each, a case of elements of earth, metal, fire, wood, and water. If the combination of the elements is wrong, it will create a destructive energy flowing so that hamper the pace of corporate fortunes. With the approach of the study and literature review, this article will explain how the relationship between the selection of colors, shapes, letters, and numbers in accordance with Feng Shui and may still have some artistic value.
\end{abstract}

Keywords: feng shui, design, brand

\begin{abstract}
ABSTRAK
Logo yang baik merupakan cerminan dari identitas suatu perusahaan, visi dan misinya, serta rangkuman karakter perusahaan tersebut. Feng shui yang merupakan ilmu topografi kuno Tiongkok dipercaya dapat mempengaruhi keberhasilan pembuatan logo yang baik. Menurut Feng shui, setiap warna, bentuk, huruf, dan angka dapat mempengaruhi energi yang terdapat pada logo perusahaan. Dan faktor-faktor tersebut juga mempunyai pengelompokkan elemennya masing-masing, sepeti elemen tanah, logam, api, kayu, dan air. Kombinasi yang salah dalam memadukan elemen-elemen di dalamnya akan membuat energi yang produktif tidak mengalir sehingga menghambat laju keberuntungan perusahaan. Dengan pendekatan studi kaji dan literatur, artikel ini akan menjelaskan bagaimana hubungan antara pemilihan warna, bentuk, huruf, dan angka yang sesuai dengan Feng shui serta tetap mengandung nilai artistik.
\end{abstract}

Kata kunci: feng shui, desain, logo 


\section{PENDAHULUAN}

Feng shui adalah ilmu topografi kuno Tiongkok yang mempercayai bagaimana manusia dan Surga (astronomi), dan Bumi (geografi), hidup dalam harmoni untuk membantu memperbaiki hidup dengan menerima Qi (energi) positif. Feng shui terdiri dari dua suku kata, yaitu Feng/Hong yang berarti angin dan Shui/Sui yang berarti air.Angin dan air dipercaya merupakan komponen penting dalam mengisi peradaban manusia untuk membentuk perilaku dan sifat alam semua mahluk di bumi ini. Dan penataan energi angin dan air jika dilakukan dengan benar dapat melimpahkan keberuntungan bagi kehidupan.

Logo atau brand merupakan sebuah tanda/lambang/sign yang mengandung unsur gambar dan tulisan sebagai identitas suatu perusahaan. Logo yang hanya terdiri dari gambar saja disebut logogram, sedangkan yang hanya tersiri dari tulisan saja disebut logotype. Dalam sebuah logo tidak hanya mengandung makna nama perusahaannya saja, tetapi merupakan perwujudan rangkuman pengalaman dan harapan perusahaan, menampilkan citra dan karakter perusahaan tersebut.

Pemilihan tulisan atau gambar yang akan dipakai untuk sebuah logo harus disesuaikan berdasarkan fungsinya, tidak hanya berdasarkan nilai estetis. Memilih menggunakan tulisan saja jika: (1) memiliki nama yang sudah baik, unik, dan berbeda serta popular di masyarakat; (2) ingin membuat orang lebih fokus pada namanya saja; (3) ingin membuat orang lebih jelas menangkap hubungan antara sub brand dengan master brand-nya.

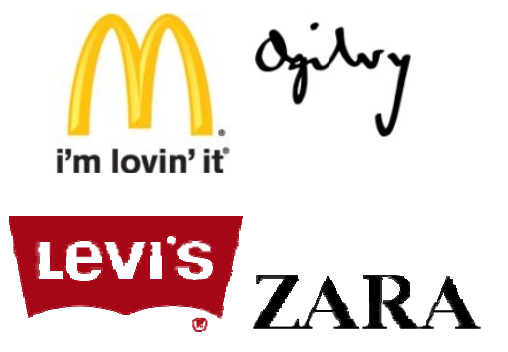

Gambar 1 Contoh Logotype

Memilih menggunakan gambar saja jika: (1) nama yang dimiliki banyak dipakai atau mirip dengan perusahaan lain; (2) nama terlalu panjang atau sulit diterjemahkan ke bahasa lain; (3) nama kurang menggambarkan brand personality-nya; (4) ingin menerapkan gambar pada media tertentu.

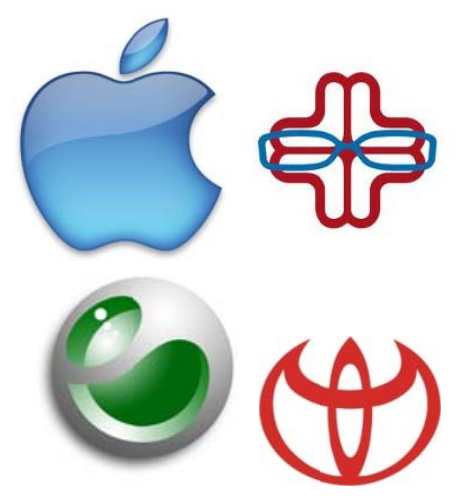

Gambar 2 Contoh Logogram 
Karena banyaknya komponen yang mempengaruhi citra sebuah perusahaan, yaitu SDM, lokasi kantor, pelayanan, jenis usaha, sejarah, logo, visi dan misi, dan lain-lain, maka sebuah logo menjadi sangatlah penting dan harus diperhatikan dalam pembuatannya. Warna, bentuk, gambar, dan komposisi logo dapat membangun kesan suatu perusahaan bahkan dapat mempengaruhi kebonafitan perusahaan tersebut. Dalam ilmu Feng shui, logo berperan juga sebagai penentu hubungan antar karyawan dan mempengaruhi daya tarik konsumen kepada suatu produk.

Syarat logo yang baik dan menguntungkan adalah (1) mewakili citra serta mencerminkan aktivitas dan fungsi yang dilogokan; (2) sederhana dengan elemen yang seminimal mungkin. Karena mata manusia memiliki kemampuan menyerap yang terbatas dalam melihat elemen-elemen yang tidak saling berhubungan; (3) orisinil, tidak sama dengan logo lain yang sudah pernah ada; (4) mengandung nilai artistik.

Kepopuleran Feng shui sejak tahun 1980-an membuat banyak perusahaan, terutama perusahan swasta, beramai-ramai mengganti logo dengan harapan akan memperoleh keuntungan lebih banyak. Dan memang tidak sedikit dari perusahaan tersebut yang menjadi lebih sukses setelah logo mereka berubah. Contohnya Bank BII, Bank Danamon, Bank BNI, Gramedia, dan lain-lain.
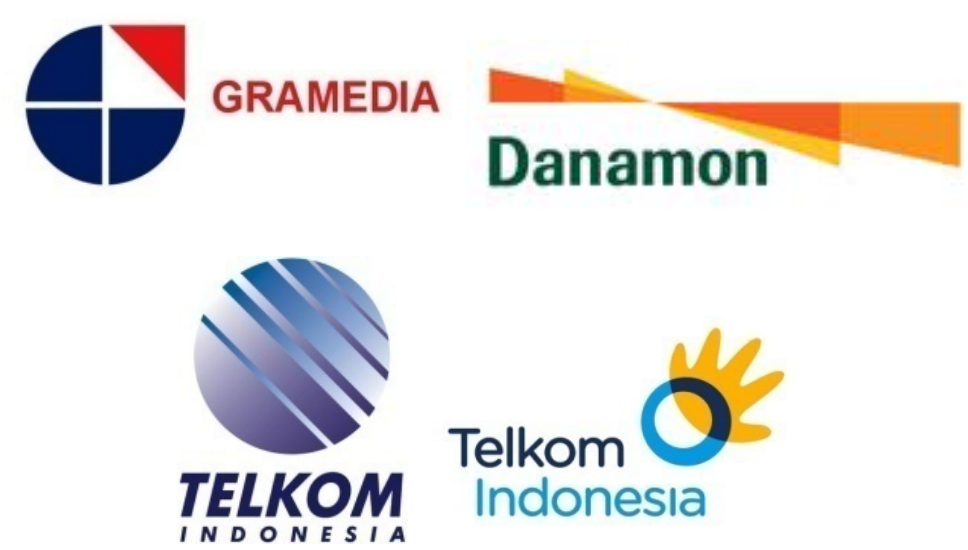

Gambar 3 Contoh Logo Perusahaan yang Berubah

Alasan terrbesar perusahaan-perusahaan tersebut mengganti logo mereka selain karena ingin mengubah citra perusahaan atau wajah perusahaan, mereka juga ingin mengubah motivasi dasar perusahaan yaitu menjadi lebih sukses dan lebih dipercaya masyarakat luas. Dan perubahan yang mereka lakukan sangat erat kaitannya dengan pengaruh Feng shui. Beberapa alasan logo harus memperhatikan Feng shui adalah: (1) untuk meningkatkan getaran logo; (2) memberikan energi pada logo agar menjadi magnet bagi peluang yang baik dan kemakmuran; (3) mengoptimalkan pertumbuhan dan keberhasilan; (4) meningkatkan faktor keberuntungan; (5) memberikan keuntungan lebih dari pesaing; (6) menghindari pengaruh negatif; (7) menambah nilai dan citra unik produk.

Logo yang dianggap menyiratkan keberuntungan bila unsur-unsurnya sesuai dengan Feng shui atau Hong shui. Kriteria Feng shui untuk logo yaitu (1) aliran Chi (energi): garis-garis melengkung, lingkaran, fokus, dan mengarah ke atas; (2) Yin dan Yang : harmonis dan seimbang; (3) sesuai dengan 5 elemen Feng shui: air, api, logam, tanah, dan kayu; (4) simbolik: gambar, bentuk, warna, dan metafor. 


\section{METODE PENELITIAN}

Penulisan menggunakan pendekatan studi kaji dengan melihat pengalaman-pengalaman dan pengamatan pribadi dan orang lain di lingkungan kerja. Selain itu didukung dengan studi literatur, yaitu mencari berbagai sumber yang terkait dengan Feng shui dan logo dari media cetak maupun media elektronik. Sumber informasi diseleksi, dievaluasi, dan dijadikan pendukung dalam penulisan ini.

\section{HASIL DAN PEMBAHASAN}

\section{Elemen}

Sebelum membuat sebuah logo, harus diketahui dulu jenis usaha dari perusahaan tersebut. Karena menurut Feng shui setiap jenis usaha ada elemen dasarnya yang akan mempengaruhi kesinambungan kinerja elemen-elemen lain yang terkait di dalamnya agar terjadi siklus produktif dalam perusahaan tersebut.

Elemen-elemen dalam Feng shui dan keterkaitannya dengan jenis bidang usaha adalah sebagai berikut: (1) elemen kayu: alat pertukangan, perkayuan, mebel, buku, kerajinan kayu, fashion/konveksi, pendidikan/kursus, konsultan, notaries, seni, penulis, desainer; (2) elemen api: bengkel las, toko elektronik, lampu, koki, restoran, bahan kimia, pemasaran, pengacara, hiburan, diskotik, kasino, senjata api, kaca; (3) elemen tanah: properti, tanah, kontraktor, bahan bangunan, kerajinan, batu, permata, makanan jadi, keramik, batu alam, hasil bumi, supermarket, toko kelontong; (4) elemen logam: kontraktor baja, toko besi, kendaraan bermotor, mesin, pabrik, perhiasan, logam, investasi, pergudangan, tabungan, peralatan logam, bengkel besi/mesin; (5) elemen air: taman, berdagang minuman, ikan hias, pelayanan, distributor, trading, perkreditan, biro perjalanan, hotel, telekomunikasi.

Siklus dalam Feng shui terbagi menjadi dua macam yaitu siklus produktif dan siklus destruktif. Elemen logo sebaiknya mendukung siklus produktif contoh bisnis yang berelemen air logo harus mengandung elemen logam/air. Siklus produktif berjalan dalam urutan kayu menjalankan api, api mengeraskan tanah, tanah melahirkan logam, logam memproduksi air, air menghidupkan kayu. Siklus destruktif berjalan dalam urutan kayu merusakkan tanah, tanah membendung air, air mematikan api, api melelehkan logam, logam mematahkan kayu.

Tabel 1 Siklus Elemen dalam Feng Shui

\begin{tabular}{ccc}
\hline Elemen & Mendukung & Merusak \\
\hline Kayu & Api & Tanah \\
Api & Tanah & Logam \\
Tanah & Logam & Air \\
Logam & Air & Kayu \\
Air & Kayu & Api \\
\hline
\end{tabular}




\section{Bentuk}

Ada 5 bentuk yang sering digunakan untuk pembuatan logo, yaitu: bulat atau setengah lingkaran (unsur logam); empat persegi dengan perbandingan lebar dan panjang minimal 1:3 atau sebaliknya (unsur kayu); empat persegi dengan perbandingan lebar dan panjang di bawah 1:3 atau sebaliknya (unsur tanah); gambar air mengalir tinggi ke rendah (unsur air); segitiga atau bentuk runcing (unsur api). Contohnya adalah logo Pertamina yang berbentuk segi empat melambangkan elemen tanah. Didukung dengan warna merah (api), biru (air), dan hijau (kayu), tampak ada sinergi yang kuat antara logo dengan elemen usaha pertambangan dan gas bumi tersebut dan diharapkan akan menjadi ramah lingkungan.

Dalam Feng shui, penggabungan dua atau lebih bentuk-bentuk elemen tersebut haruslah dalam perhitungan yang matang karena jika salah akan membawa hasil yang merugikan. Misalnya bentuk lingkaran dipadukan dengan bentuk segitiga karena lingkaran berunsur logam dan segitiga berunsur api, dan api melelehkan logam. Akan lebih baik jika bentuk lingkaran dipadukan dengan bentuk persegi (air) karena air menghidupkan kayu. Logo yang berbentuk melingkar atau berliku 'lebih aman' daripada bersisi dan bersudut tajam. Karena bentuk yang bersudut tajam mengartikan panah beracun yang memberikan energi yang buruk.

\section{Warna}

Warna merupakan hal yang penting karena selain menambah keseimbangan, warna juga bisa mewakili suatu makna yang ingin diungkapkan serta untuk menunjang aspek artistik. Warna juga digunakan untuk menyiratkan falsafah atau cita-cita pemilik logo, misalnya merah menyiratkan kebahagiaan dan keberuntungan, dan biru menyiratkan spiritualisme dan berkah. Tetapi ada warnawarna yang tidak dapat dipadukan karena adanya perbedaan dasar elemen warna tersebut, misalnya merah (api) dan hitam (air), putih (logam) dan hijau (kayu). Perpaduan warna juga harus mempertimbangkan aspek Yin (warna dingin) dan Yang (warna hangat).

Beberapa warna dalam Feng shui memiliki simbol yang berbeda-beda, yaitu: (1) warna hitam dan biru melambangkan kedinamisan, intelektualitas, dan romantik; (2) warna kuning dan coklat melambangkan materi, kekayaan, dan properti; (3) warna hijau melambangkan pertumbuhan, kemantapan, dan prestasi akademis; (4) warna emas dan putih melambangkan daya juang, kekuatan, dan karir; (5) warna merah dan ungu melambangkan kebahagiaan, perayaan, dan kedudukan.

Berikut ini dijabarkan beberapa warna dan artinya dalam Feng shui, antara lain (1) merah (api): hangat, kaya, rasa malu, kebencian; (2) pink (api): kegembiraan, romantis, kemurnian; (3) ungu (api): impresif, spiritual, gairah, energik, memotivasi, kesedihan, menekan; (4) biru (air): spiritualitas, kedamaian, misteri, kesabaran, kontemplasi, kepercayaan, stabilitas, melankolis; (5) hijau (kayu): pertumbuhan, kesuburan, harmoni, menyegarkan, meneduhkan, optimism, kebebasan, keseimbangan, permusuhan, curang; (6) kuning (tanah): pencerahan, menstimulasi pikiran, optimism, akal, ketegasan, berlebihan.

Tabel 2 Hubungan Warna dan Elemen Feng Shui

\begin{tabular}{ll}
\hline Elemen & Warna \\
\hline Kayu & Hijau tua, hijau terang \\
Api & Merah, orange, pink \\
Tanah & Kuning, coklat \\
Air & Biru, hitam \\
Logam & Putih, kuning emas, perak \\
\hline
\end{tabular}




\section{Angka}

Jika nama perusahaan atau logo yang dipakai menggunakan angka, maka keberadaan angka pada logo tersebut harus juga memperhitungkan segi Feng shui-nya.

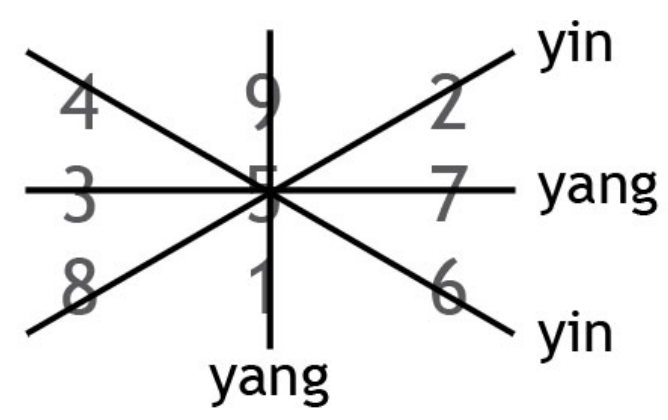

Gambar 4 Yin Yang pada Angka

Ada beberapa angka yang tidak boleh digunakan untuk jenis usaha tertentu, contohnya 9, 7, 5 tidak cocok digunakan untuk usaha yang berhubungan dengan agrobisnis, studio seni, dan studio desain. Yang cocok adalah angka 8.

Beberapa pengertian angka menurut Feng shui yaitu (1) angka 1: satu, satu-satunya, saya, diri sendiri, disebut Bintang Uang, selalu menguntungkan, merupakan angka air; (2) angka 2: mudah, gampang, membawa kemajuan di bidang militer; (3) angka 3: hidup, mendapatkan, memudahkan; (4) angka 4: mati, miskin, susah, namun memajukan bidang pendidikan dan karya tulis; (5) angka 5: tidak akan, tidak pernah, tidak bisa, paling sulit dikombinasikan; (6) angka 6: menuju, akan, membawa keberuntungan, namun tidak boleh berdiri sendiri; (7) angka 7: tepat, hoki, pasti; (8) angka 8: makmur, keberuntungan ekstra; (9) angka 9: sukses, panjang, lama, keberuntungan masa depan.

Kombinasi beberapa angka pun bisa memiliki arti yang beraneka ragam, contohnya: 168: saya akan makmur; 328: menemukan kemudahan untuk makmur; 28: mudah makmur; 54: tidak akan susah; 78: pasti makmur. Kombinasi angka yang dijauhi, contohnya: 64: akan miskin; 74: pasti miskin; 58: tidak akan makmur; 24: mudah mati; 34: hidup susah.

\section{Huruf}

Dalam Feng shui, penggunaan huruf sangatlah ditentukan oleh dua hal yaitu keseimbangan dan kecocokan. Dalam pertimbangan keseimbangan, setiap huruf digolongkan dalam Yin dan Yang. Untuk mencapai keseimbangan yang menguntungkan, kombinasi huruf (inisial atau huruf penuh) haruslah mengandung unsure Yin dan Yang dalam porsi yang sama.Misalnya huruf A akan seimbang jika dipasangkan dengan huruf C. Huruf A tergolong Yin dan huruf C tergolong Yang. Huruf $t$ cocok jika dipasangkan dengan K, L, O, atau; karena $t$ merupakan Yin dan K, L, O, S adalah Yang.

Dari segi perpaduan unsur, setiap huruf digolongkan ke dalam lima unsur yaitu logam, air, api, tanah, kayu. Karenanya, kombinasi huruf haruslah sesuai dengan kelima unsur tersebut. Misalnya, huruf $b, f, h, m, p$ (air) cocok bila dipadukan dengan huruf $c, q, r, s, x, z$ (emas) dan a, $w, y, o, l, u, v$ (tanah). Dari tipe bisnis, penggunaan huruf juga harus sesuai dengan tipe bisnis tertentu. Misalnya, bisnis yang berhubungan dengan makanan atau minuman cocok bila menggunakan huruf D, J, L, N, T, $\mathrm{Z}$ sebagai huruf penuh atau bagian dari inisial-inisial nama. 


\section{PENUTUP}

Logo yang merupakan tanda atau lambang identitas sebuah perusahaan juga harus dapat mencerminkan visi dan misinya serta karakter dari perusahaan tersebut. Sebuah logo juga mencerminkan keinginan pemilik perusahaan untuk dapat meraih keuntungan lebih baik lagi. Maka dari itu, ilmu Feng shui sebagai ilmu topografi kuno Tiongkok banyak membahas juga tentang pengaruh energi yang mempengaruhi pembuatan logo. Pemilihan warna, bentuk, huruf, angka sangat mempengaruhi keberhasilan sebuah logo untuk membawa perusahaan meraih apa yang ingin dicapai. Keseimbangan Yin dan Yang pun merupaka salah satu faktor penting yang harus diperhatikan. Terlebih setelah sekitar tahun 1980-an semakin banyak perusahaan-perusahaan, terutama perusahaan swasta, yang mulai mengganti logo mereka untuk mencitrakan kembali visi dan misinya yang baru dan terbukti sebagian bedar dari perusahaan tersebut semakin maju dan dikenal di masyarakat.

\section{DAFTAR PUSTAKA}

Brown, S. (1998). Feng shui bussines. London: Ward Lock.

Hari, A. R. (1999). Feng shui for health and wealth. Bangalore: Ramya Mudrana.

Meltzer, C. S., \& Andrusia, D. (2003). Feng shui chic. New York: Fireside Rockefeller Center.

Rustan, S. (2009). Mendesain logo. Jakarta: Gramedia Pustaka Utama. 